\title{
ANALISIS PENGEMBANGAN ALGORITMA PORTER STEMMING DALAM BAHASA INDONESIA
}

\author{
Arie Atwa Magriyanti \\ Sekolah Tinggi Elektronika dan Komputer PAT \\ arie.atwa@stekom.ac.id
}

\begin{abstract}
Abstrak
Stemming adalah metode untuk mencari kata dasar dari sebuah kata. Stemming merupakan salah satu tahapan dalam pre processing. Proses stemming memiliki pengaruh dalam tingkat akurasi temu kembali informasi. Stemming dilakukan dengan cara menghilangkan imbuhan yang terdapat pada kata. Berbagai algoritma dikembangkan untuk proses stemming bahasa indonesia, salah satunya adalah algoritma porter. Algoritma porter banyak dikembangkan oleh peneliti untuk mendapatkan efektifitas stem yang lebih baik. Dalam perkembangannya algoritma porter yang telah dimodifikasi jika dibandingkan dengan algoritma porter tala memiliki hasil yang berbeda. Hasilnya, algoritma porter yang telah dimodifikasi memberikan tingkat presisi dan recall yang lebih baik.
\end{abstract}

Kata kunci: bahasa indonesia, information retrieval, porter, stemming,

\section{PENDAHULUAN}

Stemming adalah metote yang digunakan untuk menghilangkan imbuhan dari sebuah kata. Stemming merupakan salah satu tahapan dalam pre processing. Memiliki pengaruh terhadap tingkat relevansi temu kembali informasi seperti dalam pencarian informasi berdasarkan query. Untuk mendapatkan kata dasar beberapa imbuhan yang dihilangkan adalah awalan, akhiran dan sisipan.

Tidak seperti penerapan stemming dalam bahasa inggris, proses stemming dalam bahasa indonesia memiliki tingkat kesulitan lebih tinggi. Hal ini dikarenakan morfologi bahasa indonesia yang cukup beranekaragam. Sebagai contoh terdapat kata memilikikah, dalam kata tersebut kata dasar adalah milik dengan 3 imbuhan yang diberikan yaitu awalan me-, akhiran -i dan partikel -kah.

Terdapat dua metode untuk proses stemming yaitu dengan berdasar kamus dan rule based. Beberapa algoritma yang digunakan seperti algoritma Nazief dan Adriani, Vega, Arifin dan Setiono dan Porter. Setiap algoritma dengan penerapan yang berbeda-beda. Jika Algoritma nazief dan adriani menggunakan metode kamus maka algoritma vega dan porter dengan menggunakan rule based. Kelebihannya jika dibandingkan dengan metode kamus, algoritma berdasar rule based memiliki tingkat komputasi dan tingkat akurasi stem yang yang lebih rendah.

Paper ini akan membahas salah satu dari algoritma tersebut, yaitu algoritma porter dan pengembangan. Algoritma porter yang pertama kali dikembangkan adalah porter tala, dan sampai dengan saat ini porter tala (original) banyak dikembangkan oleh peneliti untuk bisa meningkatkan tingkat presisi dan recall temu balik informasi. Beberapa hal yang dikembangkan pada algoritma porter seperti rule dan tahapan stemming yang dilakukan. Jika dibandingkan dengan algoritma porter original, algoritma porter yang telah dimodifikasi/dikembangkan memiliki tingkat presisi yang jauh lebih baik.

\section{IMBUHAN BAHASA INDONESIA}

Imbuhan adalah morfem yang ditambahkan pada kata dasar untuk membentuk sebuah kata Beberapa jenis imbuhan adalah awalan (afiks), akhiran (sufiks), sisipan (infiks), awalan-akhiran (konfiks). Imbuhan memiliki dua sifat yaitu 1 . Derifatif, jika imbuhan diberikan maka akan mengubah makna kata dasar, dan 2. Inflektif tidak mengubah makna kata dasar. Dalam implementasi algoritma porter sifat imbuhan diabaikan. Algoritma porter tidak mempedulikan makna dari 
sebuah kata. Secara umum struktur kata dasar dan imbuhan dalam bahasa indonesia adalah

[awalan] + [awalan] + kata dasar +

[akhiran] + [pengganti kepemilikan] + [partikel]

Sebagai contoh imbuhan adalah sebagai berikut

1. Awalan : per-, pe-, di-, ke-, se-, me-, ter-, di-, ber-, dll.

2. Akhiran : -i, -kan, -an, -kah, -lah, -tah, pun, -ku, -mu, -nya, dll.

Imbuhan dapat memberikan makna pada kata dasar antara lain segbagai berikut :

1. Kata kerja : imbuhan me-, ber-, per-, -kan, -i, dan ber-an.

2. Kata benda : imbuhan pe-, ke-, -an, ke-an, per-an, -man, -wan, dan -wati.

3. Kata sifat : ter-, -i, -wi, -iah, dll.

\section{STEMMING}

Stemming adalah proses ekstraksi kata dari imbuhannya untuk mendapatkan kata dasar. Hasil dari proses stemming disebut dengan stem. Penerapan proses stemming dalam setiap bahasa berbeda-beda bergantung dengan morfologi dari setiap bahasa tersebut. Untuk itu, meskipun tujuan dari proses stemming sama yaitu mendapatkan kata dasar tetap diperlukan algoritma yang berbeda-beda untuk setiap bahasa.

Algoritma adalah metode atau logika pada serangkaian tahapan kerja untuk menyelesaikan masalah. Algoritma stemming dikelompokkan menjadi dua yaitu rule based dan statis berdasar kamus. Kata dasar yang diperoleh dari algoritma tersebut terkadang mendapati error. Error dalam proses stemming dikelompokkan menjadi dua yaitu over stemming dan under stemming.

\section{ALGORITMA PORTER}

Algoritma porter ditemukan pertama kali oleh Martin Porter (1980), digunakan untuk proses stemming bahasa inggris. Algoritma tersebut kemudian dikembangkan oleh W.B. Frakes pada tahun 1992 untuk diimplemetasikan pada bahasa indonesia. Algoritma porter original yang dibahas dalam paper adalah algoritma porter yang dikembangkan oleh Fadilah Z Tala. Algoritma porter yang dikembangkan dari peneliti W.B. Frakes. Proses stemming dilakukan dengan lima langkah dengan mensimulasikan infleksi dan derivasi dari kata. Pada setiap langkah, sebuah akhiran tertentu dihapus dengan cara subtitusi. Desain dari Porter Stemmer for Bahasa Indonesia dapat dilihat pada gambar 1 .

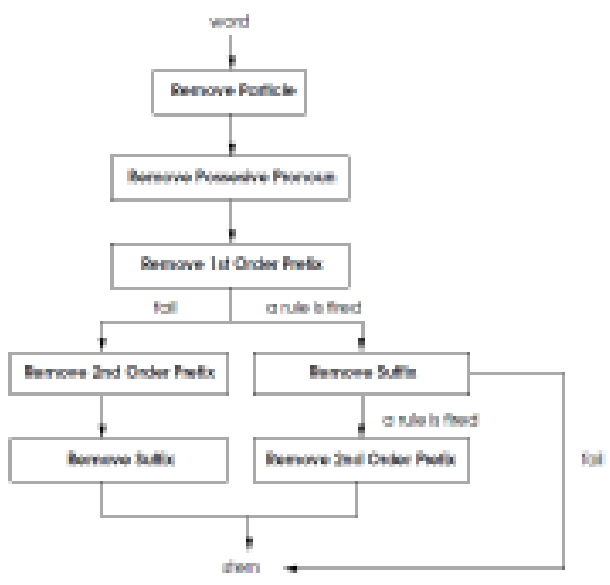

Gambar 1. Desain basic porter stemmer untuk bahasa indonesia

Algoritma porter tala dapat menangani berbagai imbuhan awalan, akhiran, awalan-akhiran dan pergantian bunyi ejaan pada morferm yang dikenai imbuhan awalan. Rule based pada algoritma stemming dibagi menjadi lima cluster. Pembagian cluster tersebut dapat dilihat pada tabel $1,2,3,4$, dan 5 .

Tabel 1. Rule based untuk partikel

\begin{tabular}{lcccl}
\hline Akhiran & Ganti & Kondisi & $\begin{array}{c}\text { Langkah } \\
\text { Tambahan }\end{array}$ & Contoh \\
\hline kah & Null & 2 & Null & $\begin{array}{l}\text { bukukah } \\
\text { buku } \\
\text { adalah } \\
\text { ada } \\
\text { lah }\end{array}$ \\
Null & 2 & Null & $\begin{array}{l}\text { apapun } \\
\text { apa }\end{array}$ \\
pun & Null & 2 & Null & \\
\hline
\end{tabular}

Tabel 2. Rule based untuk kata benda

\begin{tabular}{|c|c|c|c|c|}
\hline Akhiran & Ganti & Kondisi & $\begin{array}{l}\text { Langkah } \\
\text { Tambahan }\end{array}$ & Contoh \\
\hline $\mathrm{ku}$ & Null & 2 & Null & $\begin{array}{l}\text { bukuku } \\
\text { buku }\end{array}$ \\
\hline $\mathrm{mu}$ & Null & 2 & Null & $\begin{array}{l}\text { bukumu } \\
\text { buku }\end{array}$ \\
\hline nya & Null & 2 & Null & $\begin{array}{l}\text { bukunya } \\
\text { buku }\end{array}$ \\
\hline
\end{tabular}

Tabel 3. Rule based untuk awalan derivatif dengan perubahan bunyi huruf ke-1

\begin{tabular}{|c|c|c|c|c|}
\hline Awalan & Ganti & Kondisi & $\begin{array}{l}\text { Kondisi } \\
\text { Tambahan }\end{array}$ & Contoh \\
\hline meng & Null & 2 & Null & $\begin{array}{l}\text { mengukur } \\
\text { ukur }\end{array}$ \\
\hline meny & $\mathrm{S}$ & 2 & $\left.\mathrm{~V}^{*}\right)$ & $\begin{array}{l}\text { menyapu } \\
\text { sapu }\end{array}$ \\
\hline men & Null & 2 & Null & $\begin{array}{l}\text { menduga } \\
\text { duga }\end{array}$ \\
\hline mem & $\mathrm{p}$ & 2 & $\mathrm{~V} \ldots$ & memilah \\
\hline
\end{tabular}




\begin{tabular}{|c|c|c|c|c|}
\hline mem & Null & 2 & Null & $\begin{array}{l}\text { pilah } \\
\text { membaca } \\
\text { baca }\end{array}$ \\
\hline me & Null & 2 & Null & $\begin{array}{l}\text { merusak } \\
\text { rusak }\end{array}$ \\
\hline peng & Null & 2 & Null & $\begin{array}{l}\text { pengukur } \\
\text { ukur }\end{array}$ \\
\hline peny & $\mathrm{s}$ & 2 & V ... & $\begin{array}{l}\text { penyapu } \\
\text { sapu }\end{array}$ \\
\hline pen & Null & 2 & Null & $\begin{array}{l}\text { penduga } \\
\text { duga }\end{array}$ \\
\hline pem & $\mathrm{p}$ & 2 & $V_{\ldots} \ldots$ & $\begin{array}{l}\text { pemilah } \\
\text { pilah }\end{array}$ \\
\hline pem & Null & 2 & Null & $\begin{array}{l}\text { pembaca } \\
\text { baca }\end{array}$ \\
\hline $\mathrm{di}$ & Null & 2 & Null & $\begin{array}{l}\text { diukur } \\
\text { ukur }\end{array}$ \\
\hline ter & Null & 2 & Null & $\begin{array}{l}\text { tersapu } \\
\text { sapu }\end{array}$ \\
\hline ke & Null & 2 & Null & $\begin{array}{l}\text { kekasih } \\
\text { kasih }\end{array}$ \\
\hline
\end{tabular}

* ) perubahan bunyi vokal

Tabel 4. Rule based untuk akhiran derivatif

\begin{tabular}{|c|c|c|c|c|}
\hline $\begin{array}{c}\text { Akhira } \\
\text { n }\end{array}$ & $\begin{array}{c}\text { Gant } \\
\mathbf{i}\end{array}$ & $\begin{array}{c}\text { Kondi } \\
\text { si }\end{array}$ & $\begin{array}{c}\text { Langkah } \\
\text { Tambaha } \\
\text { n }\end{array}$ & Contoh \\
\hline Kan & Null & 2 & $\begin{array}{c}\text { Awalan } \\
€\{\text { ke, } \\
\text { peng }\}\end{array}$ & $\begin{array}{l}\text { tarikkan } \\
\text { tarik } \\
\text { mengambilk } \\
\text { an } \\
\text { ambil }\end{array}$ \\
\hline An & Null & 2 & $\begin{array}{c}\text { Awalan } \\
€\{\text { di, } \\
\text { meng, ter }\}\end{array}$ & $\begin{array}{l}\text { makanan } \\
\text { makan } \\
\text { perjanjian } \\
\text { janji }\end{array}$ \\
\hline I & Null & 2 & $\begin{array}{c}\mathrm{V} \mid \mathrm{K} \ldots \mathrm{c} 1 \\
\mathrm{c} 1, \mathrm{c} 1 \neq \mathrm{s}, \\
\mathrm{c} 2 \neq \mathrm{i} \text { dan } \\
\text { awalan } € \\
\{\text { ber, ke, } \\
\text { peng\} }\end{array}$ & $\begin{array}{l}\text { tandai } \\
\text { tanda } \\
\text { menandai } \\
\text { tanda } \\
\text { pantai } \\
\text { panta }\end{array}$ \\
\hline
\end{tabular}

Tabel 5. Rule based untuk awalan derivatif dengan perubahan bunyi huruf ke-2

\begin{tabular}{|c|c|c|c|c|}
\hline Awalan & Ganti & Kondisi & $\begin{array}{c}\text { Langkah } \\
\text { Tambahan }\end{array}$ & Contoh \\
\hline ber & Null & 2 & Null & $\begin{array}{l}\text { berlari } \\
\text { lari }\end{array}$ \\
\hline bel & Null & 2 & Ajar & $\begin{array}{l}\text { belajar } \\
\text { ajar }\end{array}$ \\
\hline be & Null & 2 & $\mathrm{~K}^{*}$..er & $\begin{array}{l}\text { bekerja } \\
\text { kerja }\end{array}$ \\
\hline per & Null & 2 & Null & $\begin{array}{l}\text { perjelas } \\
\text { jelas }\end{array}$ \\
\hline pel & Null & 2 & Ajar & $\begin{array}{l}\text { pelajar } \\
\text { ajar }\end{array}$ \\
\hline pe & Null & 2 & Null & $\begin{array}{l}\text { pekerja } \\
\text { kerja }\end{array}$ \\
\hline
\end{tabular}

Data yang digukan dalam penelitan porter tala adalah koleksi berita satu tahun dari http://kompas.com (januari 2001 s.d. desember 2001) dengan total keseluruhan sebanyak 3160 dokumen. Dalam pengujiannya, algoritma porter tala dibandingkan dengan algoritma nazief dan dievaluasi menggunakan metode paice. Metode paice akan mengindetifikasi error yang terjadi dalam proses stemming dan idealnya stemmer yang baik adalah stemmer yang berhasil menjadikan kata bentukan menjadi bentuk dasarnya.

Evaluasi paice menggunakan tiga class yang berbeda, antara lain indentify, semantik ekuivalen dan semantic distinc. Hasil dari evaluasi menunjukan bahwa algoritma nazief lebih baik daripada algoritma porter tala. Detail hasil dapat dilihat pada tabel 6 .

Tabel 6. Perbandingan algoritma

\begin{tabular}{|c|c|c|c|c|}
\hline Algorima & UI & OI $\times 10^{-6}$ & $S W \times 10^{-6}$ & Time \\
\hline Porter & 0,262 & 8,44 & 32,27 & 486 \\
\hline Nazief & 0.09 & 3,60 & 40,85 & 741 \\
\hline $\begin{array}{l}\text { Nazief } \\
10 \% *)\end{array}$ & 0,165 & 3,92 & 23,75 & 715 \\
\hline $\begin{array}{l}\text { Nazief } \\
20 \% *)\end{array}$ & 0,31 & 4,46 & 14,41 & 696 \\
\hline $\begin{array}{l}\text { Nazief } \\
30 \% *)\end{array}$ & 0,384 & 4,52 & 11,78 & 668 \\
\hline $\begin{array}{l}\text { Nazief } \\
40 \% *)\end{array}$ & 0,47 & 4,73 & 10,17 & 642 \\
\hline $\begin{array}{l}\text { Nazief } \\
50 \% *)\end{array}$ & 0,55 & 4,74 & 8,70 & 650 \\
\hline $\begin{array}{l}\text { Nazief } \\
60 \% *)\end{array}$ & 0,62 & 4,71 & 7,61 & 635 \\
\hline $\begin{array}{l}\text { Nazief } \\
70 \% *)\end{array}$ & 0,72 & 3,52 & 4,89 & 583 \\
\hline $\begin{array}{l}\text { Nazief } \\
80 \% *)\end{array}$ & 0,82 & 3,24 & 3,97 & 589 \\
\hline $\begin{array}{l}\text { Nazief } \\
90 \% *)\end{array}$ & 0,91 & 2,13 & 2,35 & 564 \\
\hline
\end{tabular}

Berdasarkan tabel tersebut diatas dapat terlihat bahwa algoritma nazief memilki tingkat error over stemming jauh lebih rendah daripada porter tala. Hal ini dikarenakan porter tala dalam proses stemmingnya menghilangkan string pertama terpanjang dalam setiap langkah.

Algoritma potter stemming juga menghasilkan banyak kata yang ambigu dibandingkan dengan algoritma nazie. Namun jika dibandingkan dengan algoritma nazief, algoritma ini memilki masalah pada ketergantungan kamus kata dasar dalam proses stemming. 


\section{PENGEMBANGAN ALGORITMA PORTER}

Berdasarkan dari penelitian yang telah dijelaskan pada bab sebelumnya, algoritma potter tala dibandingkan dengan algoritma nazief memilki tingkat error stem yang lebih tinggi. Untuk mengurangi tingkat error tersebut maka algoritma potter perlu ddikembangkan. Porter tala terdiri dari lima langkah, yaitu :

1. Menghilangkan partikel

2. Menghilangkan kata sandang

3. Menghilangkan awalan ke-1

4. Jika aturan nomor 3 tidak terpenuhi maka lanjut ke a, jika terpenuhi ke b

a. Hilangkan awalan ke-2 kemudian lanjut ke langkah 5a

b. Hilangkan akhiran, jika tidak ada akhiran maka diasumsikan kata dasar, jika ditemukan lanjut ke langkah $5 b$

5. a. Hapus akhiran, yang tersisa adalah kata dasar

b. Hapus awalan ke-2, yang tersisa adalah kata dasar

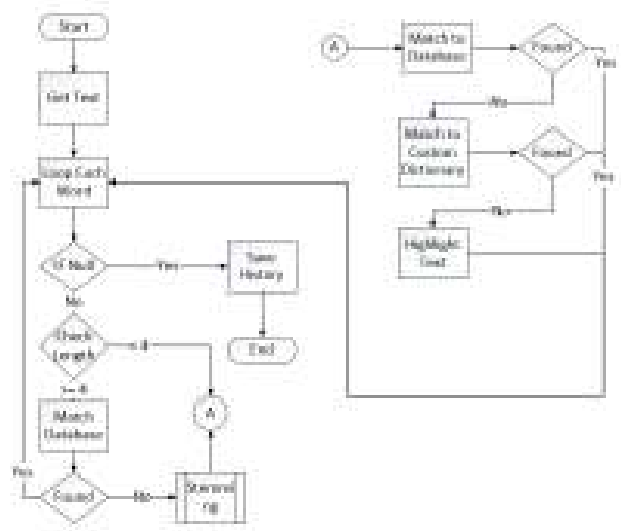

Gambar 2. Flowcart algoritma potter tala

Salah satu penelitian yang mengembangkan algoritma potter adalah penelitian yang dilakukan oleh marsel widjaya dan seng hansun. Jika algoritma potter tala menggunakan 5 langkah, maka algoritma hasil modifikasi potter tala menjadikannya 8 langkah yaitu :

1. Menghilangkan partikel

2. Menghilangkan kata sandang

3. Menghilangkan awalan ke -1

4. Jika atran nomor 3 tidak terpenuhi maka lanjut ke a, jika terpenuhi ke b

a. Hilangkan awalan ke-2 kemudian lanjut ke langkah 5a

b. Hilangkan akhiran, jika tidak ada akhiran maka diasumsikan kata dasar, jika ditemukan lanjut ke langkah $5 \mathrm{~b}$
5. a. Hapus akhiran, jika kata dasar ditemukan dalam kamus maka langkah berhenti, jika belum maka lanjut ke langkah 6

b. Hapus awalan ke-2, kata dasar ditemukan dalam kamus maka langkah berhenti, jika belum maka lanjut ke langkah 6

6. Pertama, periksa kata dasar jika ada dalam kamus maka berhenti

7. Kembali pada akhiran, jika kata dasar ditemukan dalam kamus maka berhenti

8. Periksa kamus khusus, jika ditemukan maka berhenti

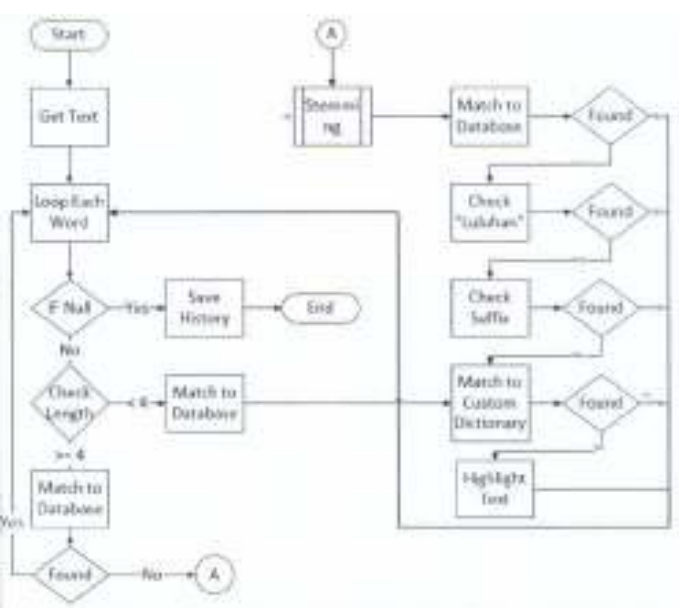

Gambar 3. Flowchart algoritma pemgembangan algoritma potter

Perbedaan yang paling mendasar dari kedua algoritma tersebut terletak pada rule based cluster awalan yang telah banyak dimodifikasi dari aslinya.

\begin{tabular}{|c|c|c|c|c|}
\hline Awalan & Ganti & Kondisi & $\begin{array}{c}\text { Kondisi } \\
\text { Tambahan }\end{array}$ & Contoh \\
\hline meng & Null & 2 & Null & $\begin{array}{l}\text { mengukur } \\
\text { ukur }\end{array}$ \\
\hline meng & $\mathrm{k}$ & 2 & $\left.\mathrm{~V}^{*}\right)$ & $\begin{array}{l}\text { mengaji } \\
\text { kaji }\end{array}$ \\
\hline meny & s & 2 & $\left.\mathrm{~V}^{*}\right)$ & $\begin{array}{l}\text { menyapu } \\
\text { sapu }\end{array}$ \\
\hline men & $\mathrm{t}$ & 2 & Null & $\begin{array}{l}\text { menari } \\
\text { tari }\end{array}$ \\
\hline men & Null & 2 & Null & $\begin{array}{l}\text { menduga } \\
\text { duga }\end{array}$ \\
\hline mem & $\mathrm{p}$ & 2 & $\mathrm{~V} \ldots$ & $\begin{array}{l}\text { memilah } \\
\text { pilah }\end{array}$ \\
\hline mem & Null & 2 & Null & $\begin{array}{l}\text { membaca } \\
\text { baca }\end{array}$ \\
\hline me & Null & 2 & Null & $\begin{array}{l}\text { merusak } \\
\text { rusak }\end{array}$ \\
\hline peng & Null & 2 & Null & $\begin{array}{l}\text { pengukur } \\
\text { ukur }\end{array}$ \\
\hline peng & $\mathrm{k}$ & 2 & $\left.\mathrm{~V}^{*}\right)$ & $\begin{array}{l}\text { pengali } \\
\text { kali }\end{array}$ \\
\hline peny & $\mathrm{S}$ & 2 & $\mathrm{~V} \ldots$ & penyapu \\
\hline
\end{tabular}




\begin{tabular}{|c|c|c|c|c|}
\hline pen & Null & 2 & Null & $\begin{array}{l}\text { sapu } \\
\text { penduga } \\
\text { duga }\end{array}$ \\
\hline pem & $\mathrm{p}$ & 2 & $V_{\ldots} \ldots$ & $\begin{array}{l}\text { pemilah } \\
\text { pilah }\end{array}$ \\
\hline pem & $\mathrm{t}$ & 2 & Null & $\begin{array}{l}\text { pemaksa } \\
\text { paksa }\end{array}$ \\
\hline pem & Null & 2 & Null & $\begin{array}{l}\text { pembaca } \\
\text { baca }\end{array}$ \\
\hline pe & Null & 2 & Null & $\begin{array}{l}\text { Perusak } \\
\text { rusak }\end{array}$ \\
\hline di & Null & 2 & Null & $\begin{array}{l}\text { diukur } \\
\text { ukur }\end{array}$ \\
\hline se & Null & 2 & Null & $\begin{array}{l}\text { sewaktu } \\
\text { waktu }\end{array}$ \\
\hline ter & Null & 2 & Null & $\begin{array}{l}\text { tersapu } \\
\text { sapu }\end{array}$ \\
\hline ke & Null & 2 & Null & $\begin{array}{l}\text { kekasih } \\
\text { kasih }\end{array}$ \\
\hline
\end{tabular}

Tidak seperti pada algoritma porter tala, pengujian pada algoritma porter modifikasi oleh marsel widjaya dan seng hansun tidak disebutkan metode apa yang digunakan dan data yang digunakan sebagai training set juga hanya sedikit yakni 200kata dalam 10 dokumen cerpen.

Hasilnya algoritma porter yang telah dimodifikasi dengan menggabungkan kamus data kedalamnya, memberikan tingkat akurasi data yang lebih tinggi daripada algoritma porter tala. Algoritma porter modifikasi sebesar 96,31\% sementara porter tala adalah 93,04\%. Hal ini dikarenakan algoritma porter modifikasi memilki rule based awalan yang lebih lengkap dan algoritma yang lebih kompleks. Detail hasil anaisis dapat dilihat pada gambar 4 .

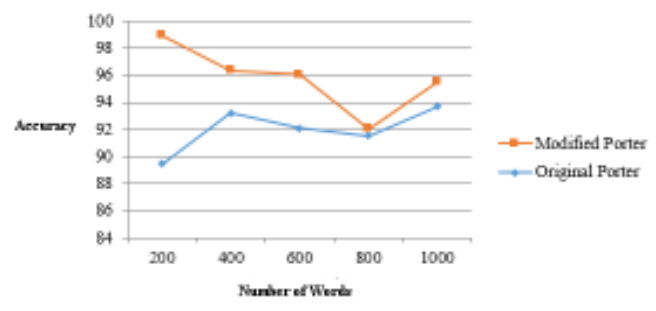

Gambar 4. Graph anaysis result perbandingan

\section{KESIMPULAN DAN SARAN}

\section{Kesimpulan}

Proses stemming adalah proses yang sangat penting dalam tahapan pre-processing. Untuk itu diperlukan pengembangan algoritma stemming secara signifikan untuk menghasilkan algoritma terbaik. Apabila dibandingkan dengan algoritma nazief, algoritma porter tala memiliki performa yang lebih rendah. Tingkat error understemming dan overstemming yang terjadi dalam proses stemming sangat tinggi.
Hal ini dikarenakan keterbatasan rule based yang digunakan dan kompleksitas algoritma yang digunakan. Untuk menangani hal tersebut maka algoritma porter perlu dikembangkan. Pengembangan algoritma porter dititikberatkan pada kelengkapan rule based dan kompleksitas algoritma yang dihasilkan. Hasilnya algoritma porter yang dimodifikasi tingkat akurasi data yang diberikan sebesar $96.31 \%$ lebih tinggi 3,27 dari algoritma porter tala.

Saran

Proses stemming dengan algoritma porter dalam paper ini masih perlu dilakukan perbaikan, untuk dapat mendapatkan tingkat presisi data yang lebih akurat maka rule based perlu lebih disempurnakan seperti menambahkan aturan-aturan dari kata berimbuhan serapan, dan atau tidak menutup kemungkinan untuk menggabungkan algoritma stemming lain seperti nazief ke dalam pengembangan algoritma porter kedepannya.

\section{DAFTAR PUSTAKA}

[1] Fadillah Z Tala. A Study of Stemming Effects on Information Retrieval in Bahasa Indonesia. Universiteit van Amsterdam, Netherlands, Thesis 2003.

[2] Jelita, dkk. Stemming Indonesian. School of Computer Science and Information Technology RMIT University, GPO Box 2476V, Melbourne 3001, Australia

[3] Marsel, Widjaya dan Seng Hansun. Implementation Of Porter's Modified Stemming Algorithm In An Indonesian Word Error Detection Plugin Application. 2: 139-150. 2015.

[4] Wahiba Ben Abdessalem Karaa. A New Stemmer to Improve Information Retrieval. Vol.5, No.4, July 2013. 